\title{
Whole Genome Sequencing
}

National Cancer Institute

\section{Source}

National Cancer Institute. Whole Genome Sequencing. NCI Thesaurus. Code C101294.

A procedure that can determine the DNA sequence for nearly the entire genome of an individual. 